\title{
EEN VEELVOUD VAN BLOEMEN: ZILVER MET BLOEMEN UIT BATAVIA
}

Verschillende eigentijdse bronnen geven aan dat in Batavia, gedurende tweehonderd jaar de hoofdzetel van de Vereenigde Oost-Indische Compagnie (VOC) in Azië, het spel van representatie en ontvangst met grote grandeur werd gevierd. Van de nauw met een grootse ontvangst verbonden zilveren tafelserviezen is relatief weinig over. Deze omstreeks 1700 in Batavia vervaardigde terrine op onderschotel is een van de weinige bekende exemplaren die met bijbehorende onderschotel bewaard gebleven is (afb. 1). Het voorwerp toont aan hoe verschillende Europese invloeden in Azië werden verwerkt. Het type is nauw verbonden met de Franse hofcultuur, de vormgeving sluit aan bij de Nederlandse mode en in de uitwerking zijn Aziatische invloeden herkenbaar.

Het idee van een compleet zilveren tafelservies ontstond in Frankrijk aan het hof van Lodewijk de Veertiende. Tegen het einde van de $17^{\mathrm{e}}$ eeuw kende men ook bij grote serviezen vaak slechts één paar kleine ronde terrines, in Frankrijk pots à l'oille genoemd, waarin de oille werd geserveerd, een soep van wild en groenten. Dit gebruik verspreidde zich al snel over Europa, en ook in Azië deed zij haar invloed gelden. Tekenend is het geschenk van een zilveren tafelservies dat Gouverneur Generaal Gustaaf van Imhoff in 1742 van de VOC kreeg. Dit in Amsterdam bestelde ensemble bestond uit: ' 18 diverse schotels, 12 achetten, 48 tafelborden, 2 koelbacken, 2 bouljonkommen, 2 lampetten en kannen, 6 schenkborden, 12 kandelaars, 2 gerandoles met kandelaars, 4 tafelkransen, 2 serviesbakjes en peperbussen, 6 suijkerbussen, 2 souskommen, 4 soeplepels, 72 lepels en 72 vorken, ..., 76 meshegten, 2 transjeer vorken en 2 mergboren'. ' Zoals gebruikelijk bestaat het servies voor een groot gedeelte uit schalen - schotels, assietten ('achetten') en schenkborden - en worden de terrines als 'bouljonkommen' aangeduid.

De zilversmid die omstreeks 1700 in Batavia deze terrine op onderschotel vervaardigde, nam daarvoor een Nederlandse vormgeving als uitgangspunt; hij sloot aan bij de bloemstijl, die tussen 1650 en 1680 in het moederland een grote populariteit genoten had. De vorm van de onderschotel doet denken aan een model dat vanaf de jaren 1660 in verschillende Nederlandse steden werd vervaardigd (afb. 2, afb. 3). De voor het Nederlandse type kenmerkende brede rand, die is opgebouwd uit acht knerren ${ }^{2}$ met weke knekelachtige omlijstingen, heeft de in Batavia werkende zilversmid vrijwel letterlijk overgenomen. Ook voor de versiering zijn parallellen aanwijsbaar. Vrijwel zonder uitzondering zijn de knerren van de Nederlandse schotels versierd met naturalistisch weergegeven bloemtakken, die schuin vanuit een onderhoek in het vlak lijken te groeien. Op dezelfde manier heeft de in Azië werkzame zilversmid zijn bloemranken weergegeven, zij het dat de Europese tuinplanten door een exotisch gewas zijnwvervangen. In plaats van anemon 


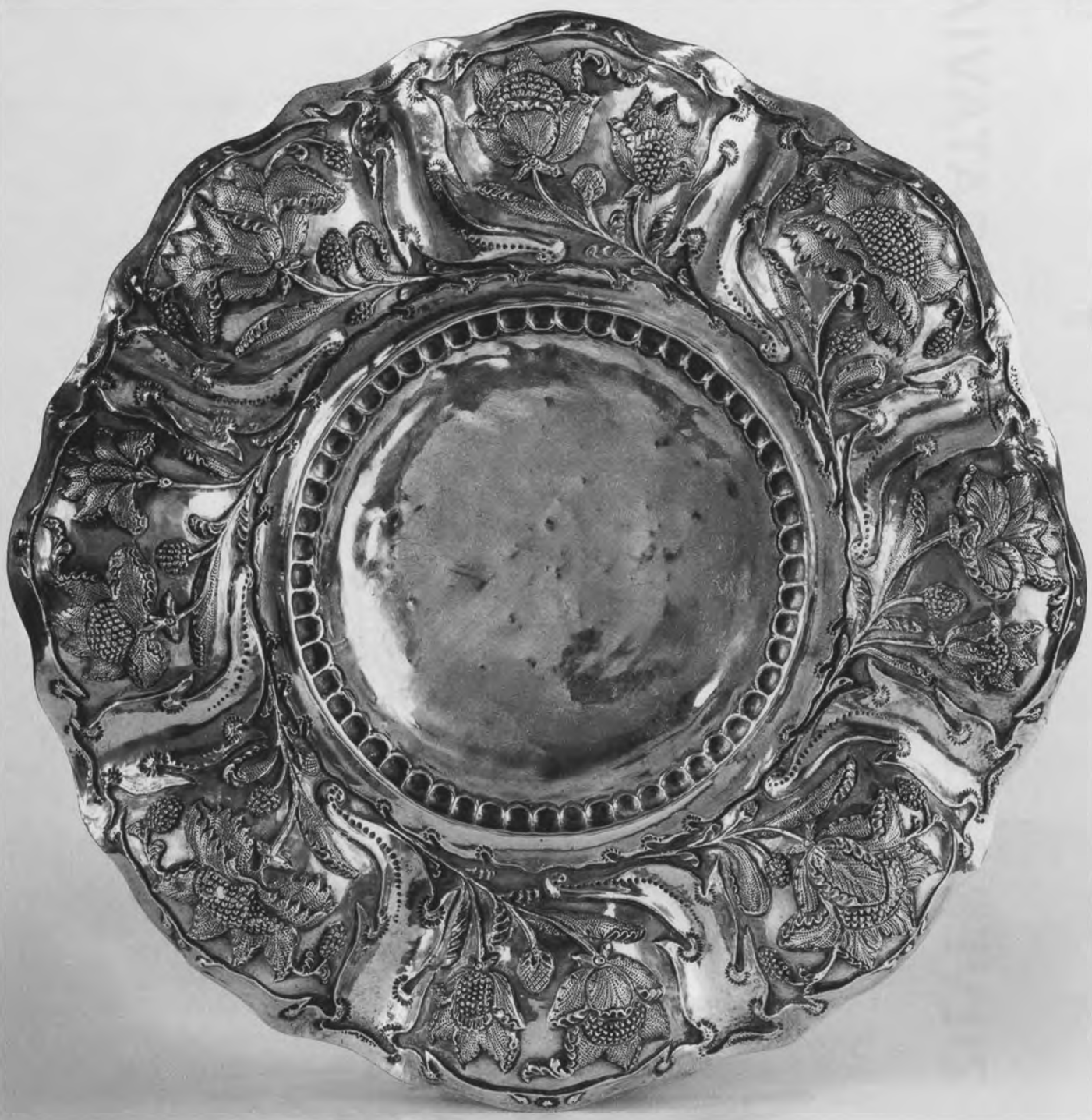

Afbeelding 2

Onderschotel van afb. 1 en tulpen zijn hier wijnranken met grote oosterse bloemen weergegeven.

De versiering van de rand van de schotel hanteerde de zilversmid vervolgens als uitgangspunt voor de versiering van de terrine. Evenals de rand van de schotel vertonen de voet, de wanden en het deksel acht knerren met knekelachtige omlijstingen, die op dezelfde manier met bloesems zijn versierd. De oosterse vertaling van een omstreeks 1700 voor Nederlandse begrippen conservatief model schotel getuigt van de Indische voorliefde voor met bloemen versierd zilver.

\section{Oosterse bloemen}

Op een moment dat die mode in Nederland zelf al over zijn hoogtepunt heen

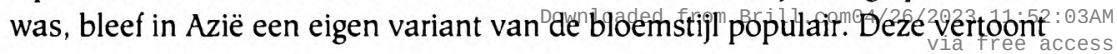




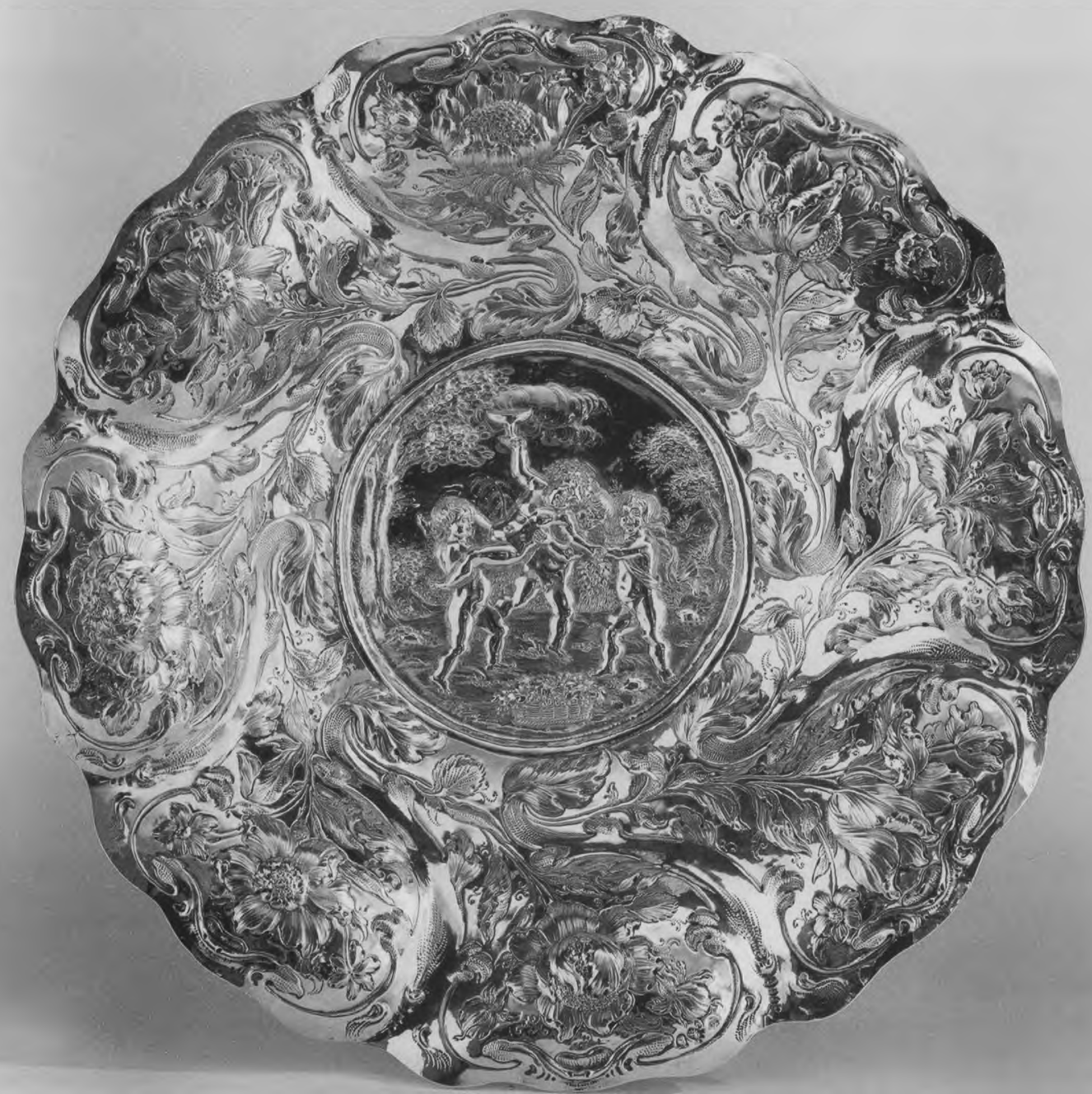

Afbeelding 3 Schotel, zilver h. $7,7 \mathrm{~cm}$., diam. $36,5 \mathrm{~cm}$. Gemerkt: stadskeur Leeuwarden, jaarletter $E=1677$, meesterteken zwaan naar links $=$ Nicolaas Mensma Rijksmuseum, inv.nr. BK-1970-1 verschillende invloeden. Naast Nederlands zilver - dat zoals onder andere blijkt uit de bestelling van de VOC in 1742 kennelijk naar Batavia werd verscheept - waren in die stad voorbeelden uit verschillende Aziatische landen voorhanden. Batavia functioneerde als marktplaats en overslagplaats voor goederen uit heel Zuidoost-Azië - porselein, metalen, lakwerk, textiel, hout en ivoor - die niet alleen naar Europa maar ook naar de omliggende landen in de regio werden uitgevoerd. De specifieke eisen die de VOC al snel aan de producten van de plaatselijke ambachtslieden in India, China en Japan stelde, leidden tot een uiterst ingewikkeld samenspel van Europese en Aziatische invloeden en had tot gevolg dat in verschillende centra voorwerpen in een nauw verwante stijl konden ontstaan. Een extra complicerende factor wordt daarbij gevormd doordat in Batavia zilversmeden werkten uit

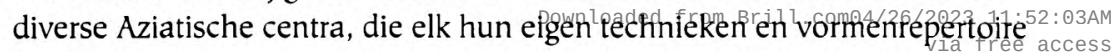



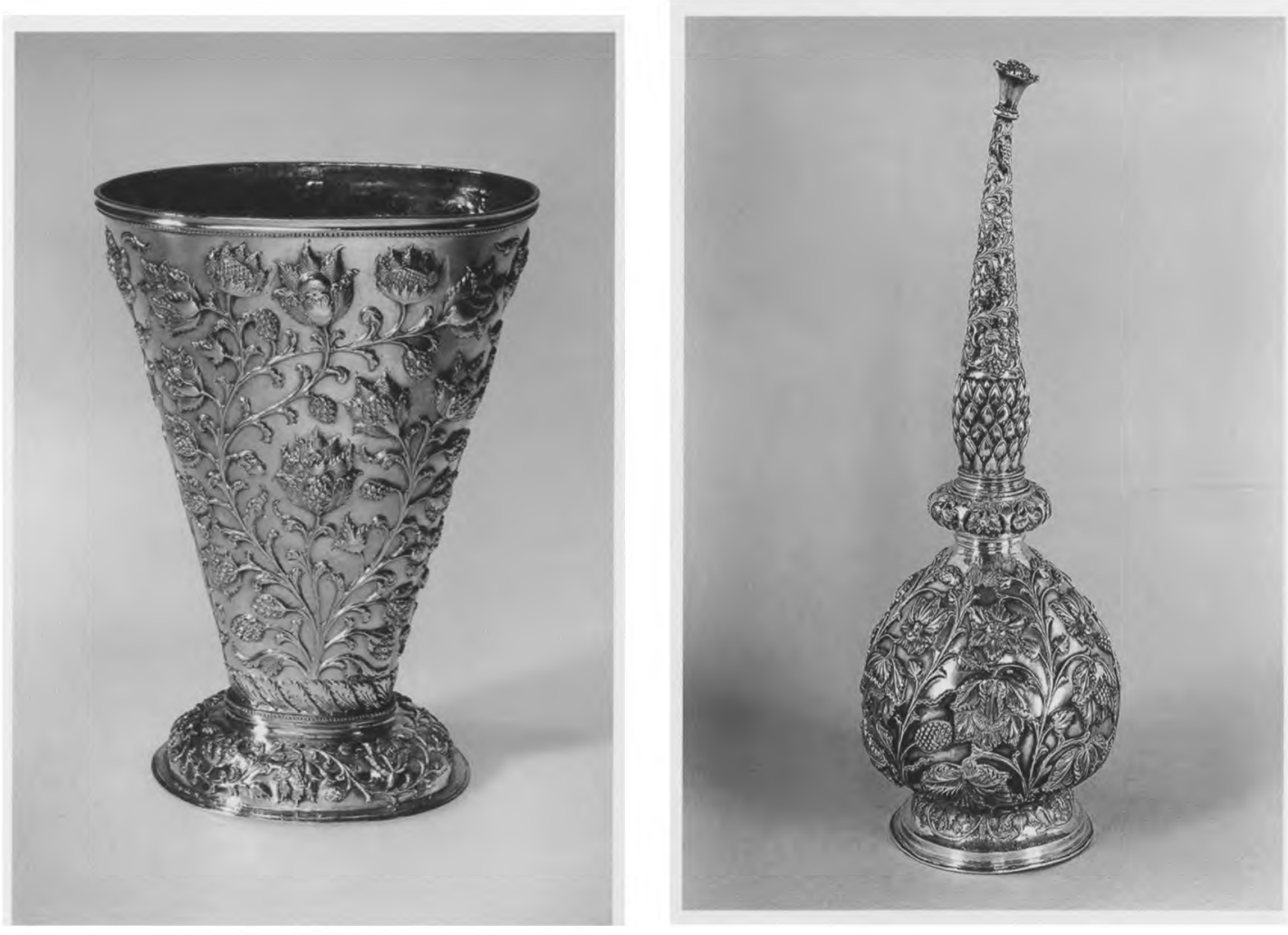

\section{Afbeelding 4 (links)} Sirihbladhouder, zilver h. $15 \mathrm{~cm}$., b. $11 \mathrm{~cm}$.

Geen merken, Batavia, Ceylon of de Coromandelkust, $18^{\text {e eeuw }}$ Rijksmuseum, inv.nr. BK-1986-20

\section{Afbeelding 5}

Rozenwatersprenkelaar, zilver

h. $29,5 \mathrm{~cm}$., d. 10,5 cm. Geen merken, Batavia, Ceylon of de Coromandelkust, $18^{e}$ eeuw Rijksmuseum, inv.nr. BK-1994-76 zullen hebben meegenomen. In de loop van de $17^{\mathfrak{e}}$ eeuw groeide vooral de groep Tamils en Bengalese ambachtslieden, die als gevolg van de hongersnoden en de oorlogen die de Coromandelkust teisterden, in slavernij vervielen. ${ }^{3}$ In Batavia werkten zij onder andere in de werkplaatsen van Europese of Euraziatische zilversmeden.

Mogelijk is het drijfwerk van de terrine en de onderschotel gemaakt door een oorspronkelijk uit India afkomstige drijver. De met grote bloemen gecombineerde wijnranken doen in de verte denken aan de door Nederlandse inmenging getransformeerde Indiase bloemmotieven op textiel en zilver, het in de tijd zelf naar de Coromandelkust genoemde 'custwerk'. ${ }^{4}$ Een met dezelfde bloempatronen versierde sirihbladhouder, die vermoedelijk in de $18^{\mathrm{e}}$ eeuw is gemaakt (afb. 4), laat zien hoe dit patroon op een kenmerkend Aziatisch voorwerp werd toegepast. Sirihbladhouders waren vermoedelijk ontstaan in kringen rond de oosterse vorstenhoven, waar het gebruik om sirih te kauwen en aan belangrijke bezoekers te presenteren al voor de Europese aanwezigheid in Azië was ontwikkeld. De met bladeren gevulde trechtervormige houder werd samen met bakjes voor de ingrediënten en andere bij het sirihgebruik noodzakelijke voorwerpen op een zilveren blad geplaatst, en in gezelschap rondgedeeld. De plaatsing van de bloeiende boom op de wand doet denken aan vergelijkbare bomen op Indiase sitsen en vooral kistjes van ivoor uit Ceylon. De boom is in het midden geplaatst en vertakt zich totdat zij

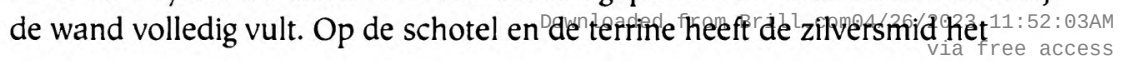




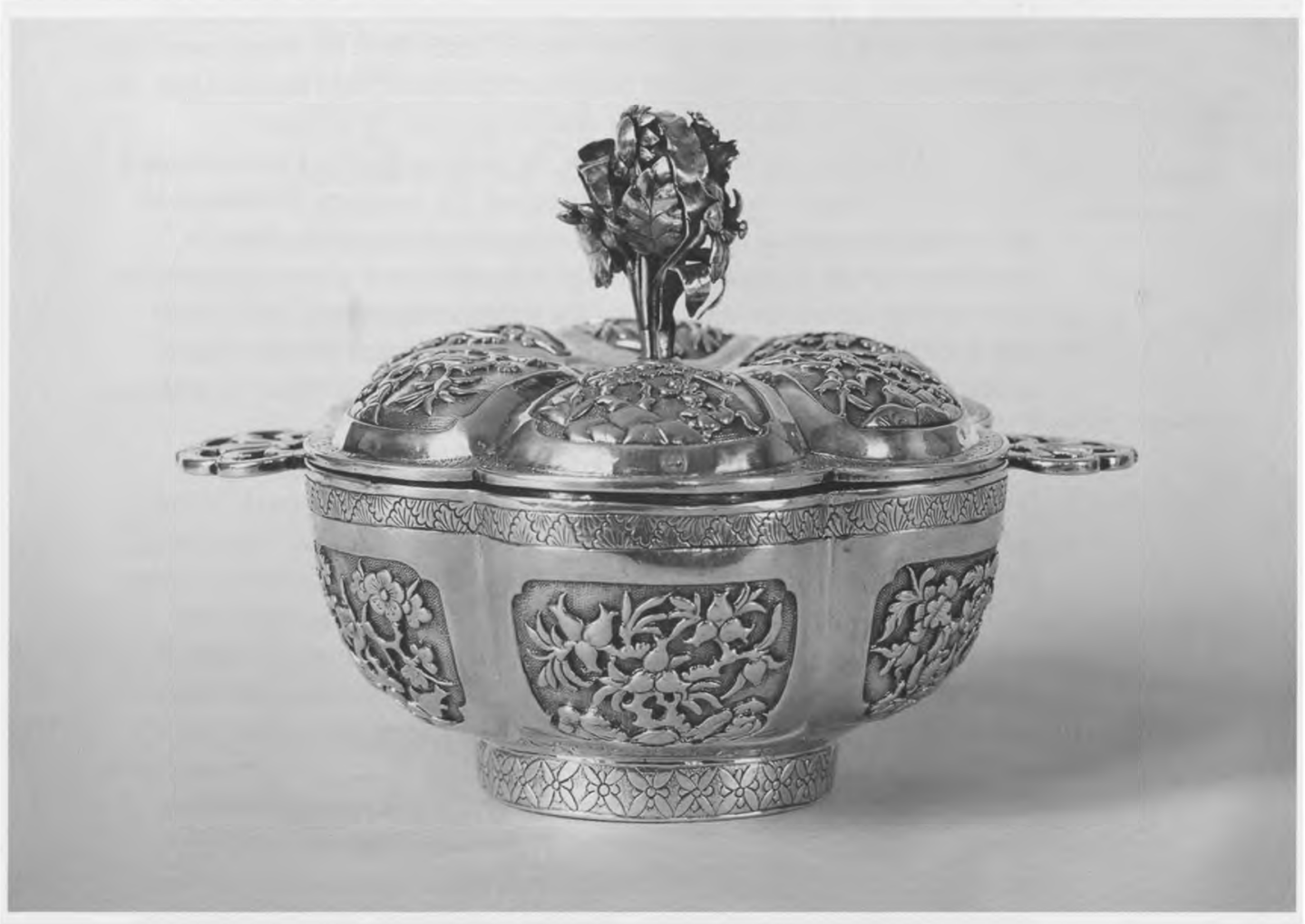

Afbeelding 6 Terrine, zilver h. 9,5 cm., b. $15,5 \mathrm{~cm}$. Gemerkt: stadskeur Batavia, letters NS en $M$, eerste kwart $18^{e}$ eeuw Rijksmuseum, inv.nr. BK-1994-77 patroon aangepast aan de Europese smaak. Zoals al eerder werd aangegeven zijn de bloesemtakken op de schotel op dezelfde manier schuin geplaatst als op het Nederlandse voorbeeld. In oorsprong Indiase bloempatronen konden ook geschikt worden gemaakt voor modellen uit het Midden Oosten, zoals de rozenwatersprenkelaar (afb. 5). Met de verspreiding van de islamitische cultuur werd dit uit Perzië afkomstige type eerst geïntroduceerd in India, vervolgens in de Indische archipel. ${ }^{5}$

De sirihbladhouder en de rozenwatersprenkelaar staan niet op zich zelf. $\mathrm{Zij}$ behoren tot een relatief omvangrijke groep met bloempatronen van dit type versierde Aziatische voorwerpen, waarvan niet met zekerheid valt vast te stellen waar, wanneer en door wie zij zijn gemaakt omdat stadskeur, jaarletter en meesterteken ontbreken. De toegepaste bloempatronen bieden op zichzelf te weinig houvast om tot toeschrijving aan een edelsmeedcentrum te kunnen komen. Zilver met dit soort bloempatronen vormde het specialisme van de oorspronkelijk van de Coromandelkust afkomstige werklieden, die in de loop van de $17^{\mathfrak{e}}$ eeuw in toenemende mate over de verschillende vestigingen van de VOC verspreid raakten. Daardoor wordt aannemelijk dat op de Coromandelkust, in Ceylon en in Batavia vergelijkbaar zilver zal zijn gemaakt. Naast zilver met in oorsprong Indiase bloempatronen, werd in Batavia ook zilver met Chinese bloempatronen verhandeld en vervaardigd. De in Batavia in eigen werkplaatsen gevestigde Chinese zilversmeden werkten er in een

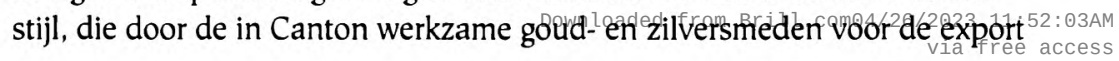


was ontwikkeld. ${ }^{6}$ Kenmerkend zijn de in verdiepte velden geplaatste, dicht geweven en op rotsjes groeiende bloesem- en vruchtenbomen, waarvan het glanzende opppervlak afsteekt tegen een gematteerde achtergrond.

Ook Europese typen werden op deze manier met takken pruimenbloesem, kersenbloesem, pioenen en perziken versierd, zoals de in het eerste kwart van de $18^{e}$ eeuw in Batavia gemaakte dekselkom met platte oren laat zien (afb. 6). Deze vertegenwoordigt een type dat doet denken aan de bekende Noordnederlandse brandewijnkommen, die gewoonlijk echter op een hogere voet staan, en slechts af en toe van een deksel zijn voorzien. De dekselkom lijkt eerder als terrine te zijn gebruikt. Gedocumenteerde exemplaren in Chinees porselein wijzen uit dat ook dekselkommen met platte opengewerkte oren als zodanig werden aangeduid. ${ }^{7}$ De rechte standring van het in zilver uitgevoerde exemplaar maakt bovendien aannemelijk dat deze de bij een terrine horende onderschotel heeft gehad, die echter niet bewaard is gebleven.

In het begin maakten we kennis met de in Batavia gebruikelijke, op representatie gerichte levenswijze, die zich onder andere vertaalde in het gebruik van zilveren serviezen. Terrines vormden daarvan het hoogtepunt. Vermoedelijk betekent dit dat zowel de in Chinese stijl gedecoreerde terrine als het met 'Indiase' bloemen versierde exemplaar in opdracht van een Europeaan zijn gemaakt. Dit wil niet zeggen dat Europeanen in Indië uitsluitend Europese of daarvan afgeleidde voorwerpen kochten. Uit verschillende, tussen 1695 en 1740 opgemaakte boedelinventarissen komt een rijk geschakeerd beeld naar voren. Zowel Europees zilver, in Indië gemaakt zilver in Europese smaak, als kenmerkend Aziatische voorwerpen konden met elkaar worden gecombineerd. Zo bezat Willem van Outhoorn, oud gouverneur-generaal van Indië in 1720 Nederlands zilver, Indisch zilver, en een grote hoeveelheid 'Japans' zilver. Oosterse voorwerpen als een sirihstel en rozenwatersprenkelaars worden respectievelijk in 1695 genoemd in de inventaris van de weduwe van een Raad van Indië, en in 1740 in de inventaris van een opperkoopman van de VOC. ${ }^{8}$ In het klein vormde de gedekte tafel van de Europeaan in Indië zo een ontmoetingsplaats van verschillende culturen, zoals de gemeenschap in Batavia in het groot een combinatie van Oosterse en Europese invloeden liet zien.

\section{Noten}

1. Geciteerd in S.M. Voskuil-Groenewegen, J.H.J. Leeuwrik, Titus M. Eliëns, Zilver uit de tijd van de Verenigde Oostindische Compagnie, Zwolle Den Haag 1998, p. 42.

2. Ook wel 'knorren': blaasvormig siermotief.

3. J. Veenendaal, 'Het meubel in Batavia', in: Wonen op de Kaap en in Batavia, tentoonstellingscatalogus Gemeentemuseum Den Haag, 2002, p. 29.

4. In de publicatie van J. Veenendaal, Furniture from Indonesia, Sri Lanka and India, Delft 1985 , wordt op pagina 49 verwezen naar notariële acten waarin met bloemen versierde zilveren schotels als 'custwerk' worden getypeerd. De bloempatronen op zilver wijken af van de onder Nederlandse invloed in India ontstane bloemtakken op textiel, die meestal een grotere verscheidenheid aan soorten bloemen laten zien. Voor enkele van de schaarse bewaard gebleven $17^{\mathrm{e}}$ eeuwse voorbeelden: E. Hartkamp-Jonxis, Sitsen uit India, Indian Chintzes, Amsterdam Zwolle 1994, cat.nr. 1 . cat.nr. 21.

5. Rozenwatersprenkelaars van dit type bleven bij Oosterse vorstenhuizen vermoedelijk lang in gebruik, getuige een verwant exemplaar dat zich tot 1837 in het bezit van de sultan van Bankalan (Madura) bevond. Desprenkelaar werdigeschonken/aansprins 2: $03 \mathrm{AM}$ 
Hendrik der Nederlanden, die in 1837 Nederlands-Indië bezocht. R. Wassing-Visser, Koninklijke geschenken uit Indonesië Historische banden met het Huis Oranje-Nassau (1600-1938), Den Haag Zwolle 1995, p. 78, afb. 46.

6. H.A. Forbes e.a., Chinese export silver. 1785 to 1885, Milton Massachusetts 1975. Ook voordien moeten voorwerpen van goud en zilver voor de export zijn gemaakt. $Z$ ij werden slechts incidenteel aangeschaft door de VOC, en zullen dus vooral door particulieren zijn besteld (C. Jörg, Porselein als handelswaar, proefschrift Kunsthistorisch Instituut Leiden 1978, p. 89). De VOC handelde wel in spiauter - een materiaal dat op zilver leek - waarvan in Canton onder andere kraantjeskannen met Chinese decoraties werden gemaakt (C. Jörg, Porselein als handelswaar, proefschrift Kunsthistorisch Instituut Leiden 1978, p. 92, p. 253 nr. 148).

7. In de bewaard gebleven nota van het 'Swellengrebel' servies wordt in 1751 een 'groote soepkom' beschreven. Daaronder werd kennelijk een ronde terrine op standring verstaan, met deksel en platte, opengewerkte oren. (D. F. Lunsingh Scheurleer, Chine de Commande, Lochem 1989, p. 172, afb. 148).

8. S.M. Voskuil-Groenewegen, J.H.J. Leeuwrik, Titus M. Eliëns, Zilver uit de tijd van de Verenigde Oostindische Compagnie, Zwolle Den Haag 1998, pp. 44-45. 


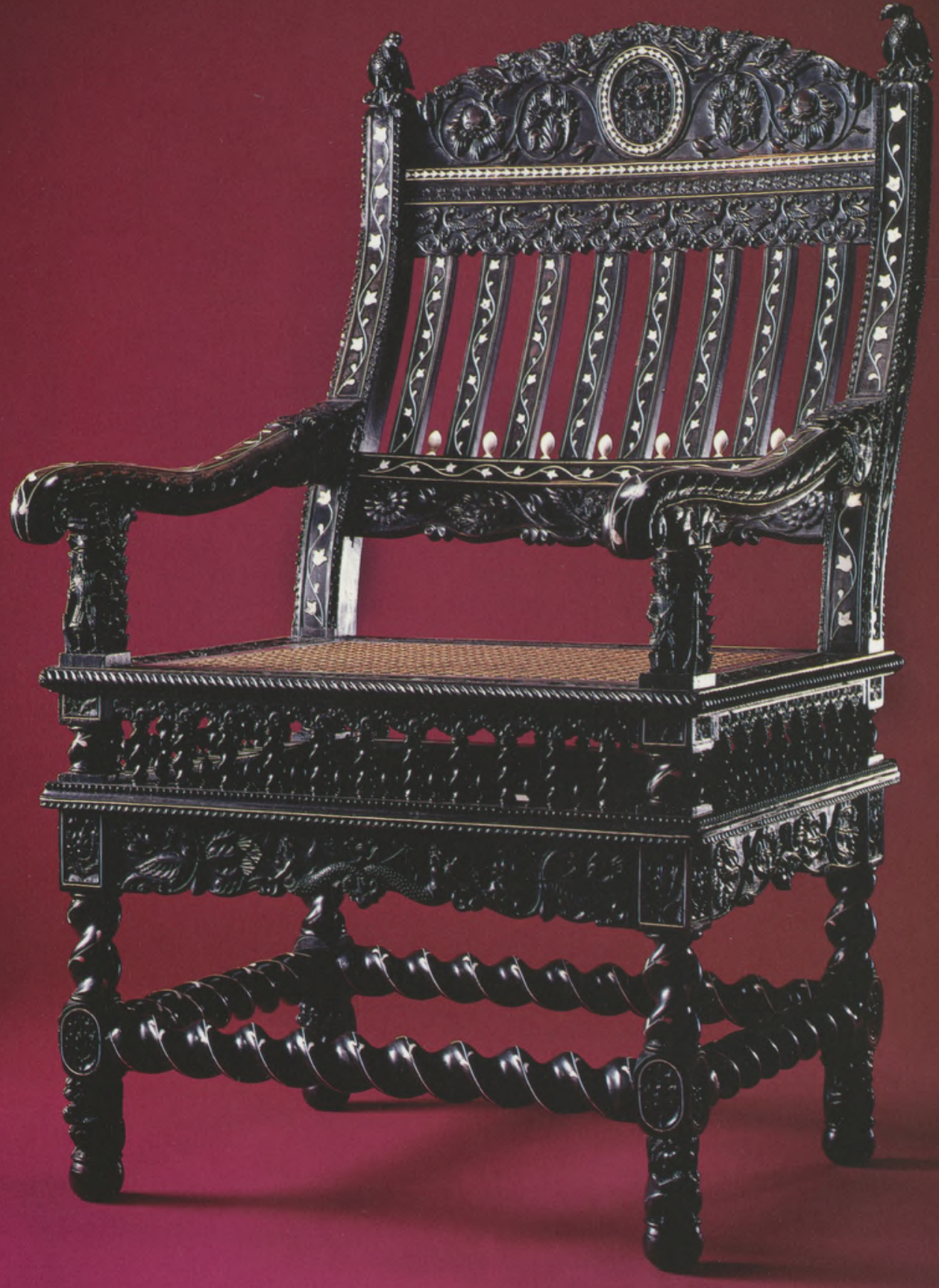

